brazilianpoliticalsciencereview

BOOK REVIEW

\title{
Diffusion of Policies, Practices and Social Technologies in Brazil*
}

\author{
by Sandra Gomes
}

Universidade Federal do Rio Grande do Norte, Brazil

(Faria, Carlos Aurélio Pimenta de; Coêlho, Denilson Bandeira, and Jard da Silva, Sidney (eds). Difusão de Políticas Públicas. São Bernardo do Campo: Publisher UFABC, 2016)

It is a welcoming introduction to the Brazilian academic community the arrival of the book 'Public Policy Diffusion', edited by Professors Faria, Coêlho and Jard da Silva. As it is stated in the opening pages of the book, the use of diffusion models is very incipient in Brazil in comparison to the level of knowledge accumulation in the international literature, especially in the USA. In this sense, it is an admirable effort to gather together ten chapters not only discussing the dissemination and adoption of public policies but also presenting a diverse collection in terms of perspectives and models possible to be used as an analytical reference.

But, in my view, this book could also be read as attempted explanations for the adoption of policies, practices and ideas in the Brazilian case. With the exception of the first chapter (by COÊLHO), which discusses analytical tools of this literature, nine out of the ten chapters include Brazil in their analysis, either as a single case or in comparison to other Latin American countries and worldwide. Although it is not the purpose of the editors, I could not avoid making connections among chapters thinking about possible general findings for the Brazilian case, which I will discuss further on.

For the unfamiliar reader, the phenomenon of policy diffusion could be summarized in the following puzzle: why and how some policies get to be considered as 'good practices' and adopted by other governments?

Let us first say that diffusion or transference of policies is not something new in

(*) http://dx.doi.org/10.1590/1981-3821201700020010 
policy systems. What is new is an academic interest to study the phenomenon and to extract regular patterns for explanation. One thing, then, is to show policies, practices or social technologies being spread or disseminated among governments, but something quite different is to attempt to explain why and how this happens in the attempt of constructing theories of policy diffusion, transfer or, more generally, learning.

Some models of explanations, concepts and types of mechanisms that could produce diffusion are presented and discussed. Although there is no unity in the use and applications of the analytical tools and concepts among authors, it is possible to extract some basic features of policy diffusion models.

We learn that countries or subnational governments may 01 . innovate, that is, adopt a new policy, program or practice; 02. emulate (adapting the original policy to local contexts and objectives) or 03. copy the original policy (associated with coercion). Innovation does not equate to invention as it is understood as "a program that is new to the government adopting it" (BERRY and BERRY, 2007). These are pioneering experiences that may lead to the spreading or adoption by other governments. Emulation does not equate to copying. It means that local conditions and actors will play a role by adapting the original policy to their own needs and beliefs. The case of copying the original policy without adaptation, argue some of the authors, would be more common in countries that do not have enough bureaucratic/state capacity and it is normally associated with the adoption of certain practices as a condition for loans from international agencies. Hence the label 'coercion' for this type of mechanism in which governments do not have, really, much of a choice.

Countries may also be analyzed as 'importers' or 'exporters' of policy innovation as some of the authors argue.

Based on the readings of the Brazilian case presented throughout the book, one learns that Brazil (also valid for other Latin American countries) has 'imported' and/or diffused domestically the ideas of economic liberalization, regulatory agencies after privatization (chapter by JORDANA), new models of reforming Public Pension (by JARDIM and JARD DA SILVA) and also models of administrative/management reforms (by ABRUCIO, SANO and SEGATTO; and also by PALOTTI, PEREIRA and CAMÕES). At the same time, the same book collection teaches us that Brazil has 'exported' policy, practices and social technologies to other countries in Latin America and the rest of the world such as the Participatory Budgeting, subject of two chapters (WAMPLER and 
PORTO DE OLIVEIRA), but there are also mentions to Bolsa-Família Program (conditional cash transfer to poor families), the program for school meals that buys food from small agricultural family-farmers (PNAE, in Portuguese) or health programs transfers such as malaria or HIV initiatives. We also find that transferring social technologies to other countries was part of the Brazilian international relations agenda during Lula's government (chapter by FARIA).

The inevitable question that arises is: could Brazil be an 'importer' or an emulator of international economic models and related public management solutions while an 'exporter' or innovator in terms of social policies and technologies? It seems to be the case from the reading of this collection. However, it is still posed as a question as there may be a biased selection of case studies: we do not know if Brazil exports 'economic practices and technologies' and, likewise, import social technologies because studies like this have not been done yet. We also do not know if the export of social technologies is a strategy adopted only by PT (the Worker's party) or if other political parties also export practices that have not been studied yet. Only future research could clarify these points by testing the proposition of Brazil as an importer of economic models and exporter of social technologies.

The book presents potentially good proposals or models for analysis but the empirical demonstration is quite limited throughout the chapters. I do not think this undermines the collection as it seems clear that the methodological challenges to measure the phenomenon of diffusion is quite significant for all of the international community dedicated to this subject. Essentially, to capture the process or mechanisms that explain how diffusion happened involves the adoption of micro-analysis to the level of individuals.

I am convinced after reading all articles in the book, that policy diffusion or transfer is impossible to take place without the role of ideas and networking. The argument is that to identify the causal mechanisms of diffusion, one has to lower to micro-foundations by observing actors. So, for example, Elkins argues in his Chapter that emulation of international constitutional models can be traced as discourses of individual constitution-makers during the Brazilian Constituent Assembly; Gonnet suggests that mapping members and their relations to epistemic communities combined with an analysis of state capacities could explain the likelihood of a country to innovate, learn, emulate or simply be imposed a policy model (coercion); Jordana traces 
professional and bureaucratic networks to explain the adoption of regulatory agencies (after privatization) in different Latin American countries in which the identification of recurrent actors could be seen as 'political entrepreneurs'; Porto de Oliveira also proposes looking into the micro-sociological level of analysis of individuals and the relations they slowly form throughout time in different places in order to explain the domestic and international diffusion of the Participatory Budgeting Program.

Another reason that makes the analysis complex is that many of the relations, connections, establishment of social or professional networks are not, necessarily, coordinated events. Conversely, many actors or groups behave to enhance the adoption or diffusion of policies at the same time in different places without necessarily coordinating action among themselves. So, the World Bank introduces the Participatory Budgeting within its agenda of disseminating decentralization, urban management and participatory governance, at the same time that another network by Brazilian and French municipalities also contributes to explain the dissemination of this policy (chapter by Porto de Oliveira). So, there is indeed a need for this micro source of information before being able to establish general patterns of diffusion.

For all these reasons, the book is an interesting introductory reading which stimulates further thinking about policy diffusion theories and empirical applications. Having said that, I feel the book missed an opportunity to present a chapter (or even a glossary) on basic definitions and concepts of policy diffusion, especially considering this is not a well-known approach for Brazilian scholars. Although some concepts appear throughout chapters, we still do not know what is actually diffusion in academic terms. Is policy diffusion a "successive or sequential adoption of a practice, policy, or program either across countries or across subnational jurisdictions" (FREEMAN, 2008, p. 369) or "the process by which an innovation is communicated through certain channels over time among members of a social system" (ROGERS, 1983 apud BERRY and BERRY, 2007)? What are the conceptual definitions (and differences) of policy diffusion, policy transfer, policy learning, policy innovation, policy emulation, policy convergence and others alike?

If 'the process of communication' is the definition, then, I find it difficult to accept that strategies adopted by Brazilian federal governments to induce subnational governments to follow national policies could be understood as a 'vertical diffusion'. Or, is the subject of diffusion to identify how the communication of the federal government 
initiative goes through subnational government channels? The strategies adopted in Brazilian federalism for education (FUNDEF or FUNDEB) or health (SUS), which contain strong incentives for adoption as well as punishment - with loss of fiscal resources - for subnational governments, could be understood as policy diffusion? And, if it is possible to classify these events as diffusion, what would be the mechanism: 'learning', 'emulating' or 'coerced' by the federal government? It may be a question still open to debate among Brazilian scholars, but the reader of the book would definitely benefit from a basic, but well informed, definition of concepts in policy diffusion, so she or he could make their own mind up on issues such as this. This is the only missing aspect of the book for me, which may be added in a future edition. However, the collection remains, up-to-date, the most comprehensive publication on this theme in Brazil.

\section{References}

BERRY, Frances Stokes and BERRY, William D. (2007), Frameworks comparing policies across a large number of political systems: innovation and diffusion models in policy research. In: Theories of the policy process. Edited by SABATIER, Paul A.. Bouldier: Westview Press. pp. 223-260.

FREEMAN, Richard (2008), Learning in public policy. In: The Oxford handbook of public policy. Edited by MORAN, Michael; REIN, Martin, and GOODIN, Robert E.. Oxford: Oxford University Press. p. 367-388. 